
Complex $\mathrm{TiO}_{2}$ Nanostructures for

SUBJECT AREAS:

MATERIALS SCIENCE

NANOTECHNOLOGY

CHEMISTRY

METHODS

Received

11 April 2012

Accepted

23 May 2012

Published

12 June 2012

Correspondence and requests for materials should be addressed to H.J.F. (fanhi@ntu.edu.

* These authors contributed equally to this work. \title{
Efficient Solar Energy Conversion
}

\author{
Jingshan Luo'*, Siva Krishna Karuturi ${ }^{2 *}$, Lijun Liư ${ }^{2}$, Liap Tat $\mathrm{Su}^{2}$, Alfred ling Yoong Tok ${ }^{2} \&$ Hong Jin Fan ${ }^{1}$
}

'Division of Physics and Applied Physics, School of Physical and Mathematical Sciences, Nanyang Technological University, 637371 Singapore, ${ }^{2}$ School of Materials Science and Engineering, Nanyang Technological University, 639798 Singapore.

$\mathrm{TiO}_{2}$ nanostructures-based photoelectrochemical (PEC) cells are under worldwide attentions as the method to generate clean energy. For these devices, narrow-bandgap semiconductor photosensitizers such as CdS and CdSe are commonly used to couple with $\mathrm{TiO}_{2}$ in order to harvest the visible sunlight and to enhance the conversion efficiency. Conventional methods for depositing the photosensitizers on $\mathrm{TiO}_{2}$ such as dip coating, electrochemical deposition and chemical-vapor-deposition suffer from poor control in thickness and uniformity, and correspond to low photocurrent levels. Here we demonstrate a new method based on atomic layer deposition and ion exchange reaction (ALDIER) to achieve a highly controllable and homogeneous coating of sensitizer particles on arbitrary $\mathrm{TiO}_{2}$ substrates. PEC tests made to CdSe-sensitized $\mathrm{TiO}_{2}$ inverse opal photoanodes result in a drastically improved photocurrent level, up to $\sim 15.7 \mathrm{~mA} / \mathrm{cm}^{2}$ at zero bias (vs $\mathrm{Ag} / \mathrm{AgCl})$, more than double that by conventional techniques such as successive ionic layer adsorption and reaction.

E ver since the seminal paper of photoelectrolysis of water by Fujishima and $\mathrm{Honda}^{1}, \mathrm{TiO}_{2}$ has received wide attentions in photocatalysts, water splitting and solar cells due to its high photoactivity, low cost and excellent chemical stability ${ }^{2-5}$. The limiting factor for $\mathrm{TiO}_{2}$ is the large band gap $(\sim 3.2 \mathrm{eV})$, which defines its light absorption only in the UV range. During the past three decades, tremendous efforts have been put to enhance the visible light harvesting ability of $\mathrm{TiO}_{2}{ }^{6}$. Heterogeneous structures have been proposed to couple $\mathrm{TiO}_{2}$ with materials exhibiting visible light harvesting ability, and the first trial was done by Serpone et al. to couple $\mathrm{TiO}_{2}$ with CdS which showed a significant improvement ${ }^{7}$. Later on Graetzel made a significant breakthrough in sensitizing $\mathrm{TiO}_{2}$ with dye molecules, viz., the dye-sensitized $\mathrm{TiO}_{2}$ photoanode ${ }^{4}$. Following the invention of Graetzel cell, quantum dot sensitized solar cells (QDSSC) quickly catch up following the mature quantum dot synthesis protocol developed by Peng and Alivisatos ${ }^{8,9}$. The key development of QDSSC was made by Kamat in 2005, with the pre-synthesized CdSe nanocrystals linked to $\mathrm{TiO}_{2}$ thin films by organic molecules ${ }^{10}$. Since then various methods of sensitization have been developed, and they can be summarized into two main categories: assembly of pre-synthesized QDs and direct growth ${ }^{11,12}$. Pre-synthesis provides the feasibility of facile control in the size, size distribution and morphology. However, the charge transfer would be retarded by the surface functional molecules. Also the loading of the sensitizer prepared by this method is usually low. Direct growth allows both a compact contact of the sensitizer with $\mathrm{TiO}_{2}$, and the ease of increasing the loading of the sensitizer. A diverse range of methods are reported for the direct coating of the sensitizing materials, such as chemical bath deposition $^{13,14}$, successive ionic layer adsorption and reaction (SILAR) ${ }^{15-17}$, electrochemical deposition ${ }^{18}$, chemical vapour deposition ${ }^{19}$ and electrophoretic deposition ${ }^{20}$.

Despite the development of various sensitization methods, the sensitizers still suffer from poor thickness and uniformity control especially for deposition on high aspect-ratio $\mathrm{TiO}_{2}$ nanostructures. As the size of QDs is much larger than dye molecules, penetration of $\mathrm{QDs}$ into $\mathrm{TiO}_{2}$ nanoarchitectures with a depth $>10 \mu \mathrm{m}$ is more difficult than the case in dye-sensitized solar cells ${ }^{11}$. Due to the quantum confinement effect and the limited charge diffusion length, the size of the QDs plays an important role in charge transfer process. The poor control in conventional deposition techniques usually leads to aggregation of QDs into large particles, thus causing high internal recombination loss.

Atomic layer deposition (ALD) is a thin film deposition technique that is based on self-limiting surface reactions by sequential exposure of the substrate to different gas phase precursors ${ }^{21}$. ALD provides precise thickness control at the angstrom or monolayer level and deposition on high aspect ratio nanostructures with 
excellent step coverage. By employing ALD for QD sensitization, excellent infiltration and conformity could be achieved, and the size of QDs could be varied simply by tuning the number of ALD cycles. Recently Stacey et al showed the ALD CdS for solid state QDSSC ${ }^{22}$. However, there is a serious safety issue for such ALD CdS process, as the precursors of dimethyl cadmium (DMCd) and hydrogen sulfide $\left(\mathrm{H}_{2} \mathrm{~S}\right)$ are highly toxic.

Liquid-phase reaction via ion exchange has been developed as a method to fabricate semiconductor heteronanostructures ${ }^{23,24}$. The principle of ion exchange is based on the solubility of the material which allows only a critical selection of the target materials. Very recently ion exchange reaction has also been employed to fabricate nanowire $\mathrm{p}-\mathrm{n}$ junctions for photovoltaics ${ }^{25}$, as well as photosensitizer layers on $\mathrm{ZnO}$ nanowires for semiconductor-sensitized solar cells ${ }^{26,27}$. Due to its amphoteric property, $\mathrm{ZnO}$ is unstable for PEC in acidic or alkaline electrolyte solution, which is the bottleneck for practical applications. On the other hand, the amphipathicity of $\mathrm{ZnO}$ makes it an ideal template for nanofabrications ${ }^{28}$.

In order to have the merit of ALD without the highly toxic source for the QD sensitization, in this work, ALD ZnO thin films were deposited on various $\mathrm{TiO}_{2}$ nanostructures as the sacrificial templates to convert to short bandgap semiconductor sensitizers by ion exchange reaction (we call the whole process ALDIER). The thickness and the size of the sensitizer could be controlled by the thickness of the $\mathrm{ZnO}$ layer and the condition of ion exchange reaction. The reproducible photocurrent levels $>15 \mathrm{~mA} / \mathrm{cm}^{2}$ is obtained using the $\mathrm{TiO}_{2}$ inverse opals (TiIO), which is so far the highest among all nanostructure $\mathrm{TiO}_{2}$-based PEC cell for hydrogen generation.

\section{Results}

Figure 1(a) illustrates the flowchart of the ALDIER based on the example of TiIO obtained by replicating a self-assembled multilayer polystyrene spheres ${ }^{29,30}$. However, the $\mathrm{TiO}_{2}$ host structures for the 3 -D homogeneous photosensitization can include a wide range of common types, for example, hydrothermal-grown nanorods, anodized nanotubes, and commercial P25 nanoparticles. In the first step, the host is coated with a layer of $\mathrm{ZnO}$ of tunable thicknesses using ALD. The second step is the ion exchange reaction. In this process the ALD $\mathrm{ZnO}$ layer serves as the sacrificial reactant which transforms first into $\mathrm{ZnSe}$ through anion exchange with the $\mathrm{Se}^{2-}$ precursor and then to the final CdSe via cation exchange with $\mathrm{Cd}^{2+}$ source ${ }^{27}$. The ion exchange reaction is based on the solubility product constant $\left(\mathrm{K}_{\mathrm{sp}}\right)$ of the material. As the constant of $\mathrm{ZnO}\left(\mathrm{K}_{\mathrm{sp}}=6.8 \times 10^{-17}\right)$ is much larger than $\mathrm{ZnSe}\left(3.6 \times 10^{-26}\right), \mathrm{ZnO}$ can be converted into $\mathrm{ZnSe}$ by anion exchange reaction with $\mathrm{Se}^{2-}$ anions. With the same principle, ZnSe can be further exchanged into CdSe $\left(6.31 \times 10^{-36}\right)$.

The sensitized TiIO is tested as the PEC photoanode in a threeelectrode system for hydrogen generation. Figure 1(b) shows the diagram of the PEC cell where a piece of Pt foil was used as the cathode. $\mathrm{H}_{2}$ gas bubbles are generated on the cathode through the water reduction reaction $2 \mathrm{H}^{+}+2 \mathrm{e} \rightarrow \mathrm{H}_{2}$, whereas the holes are scavenged by the sulfide electrolyte. As CdSe has a wider light absorption range and better conduction band edge alignment with $\mathrm{TiO}_{2}$ than $\mathrm{ZnSe}$ (see Fig. 1c), the photocurrent level of $\mathrm{TiO}_{2} / \mathrm{CdSe}$ is much higher than $\mathrm{TiO}_{2} / \mathrm{ZnSe}$, as also reported in previous work ${ }^{27}$. Thus in this experiment we focus on CdSe photosensitizer on TiIO.

The composition transformation from $\mathrm{ZnO}$ to $\mathrm{CdSe}$ is confirmed using X-ray diffractometer (see Fig. 2a). The blue solid lines are the calculated XRD peaks for Anatase $\mathrm{TiO}_{2}$ (PDF\#21-1272), and the green dashed lines are the calculated XRD peaks for $\mathrm{SnO}_{2}$ (PDF\#41-1445). All the diffraction peaks of TiIO structure on FTO correlate well with the calculated positions. The diffraction peaks of $\mathrm{ZnO}$ (PDF\#36-1451) appear only for the TiIO samples after the deposition of $\mathrm{ZnO}$. After the first step anion exchange reaction, the ZnSe peaks (PDF\#37-1463) can be detected while the $\mathrm{ZnO}$ peaks disappear, implying that the ALD $\mathrm{ZnO}$ layer is totally converted to $\mathrm{ZnSe}$. After the complete exchange reaction, the peaks can be indexed to hexagonal CdSe (PDF\#08-0459). The peak intensities of the CdSe a

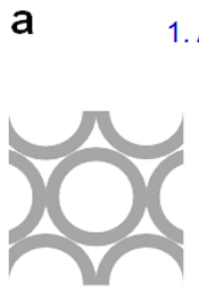

$\mathrm{TiO}_{2}$ inverse opal (TilO)

$$
\text { 1. ALD of } \mathrm{ZnO}
$$
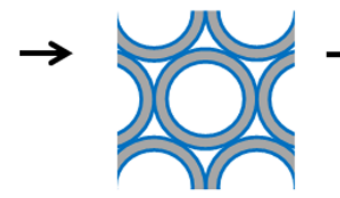

$\mathrm{TilO} / \mathrm{ZnO}$

\section{Anion exchange $\mathrm{Se}^{2-}$}

3. Cation exchange $\mathrm{Cd}^{2+}$
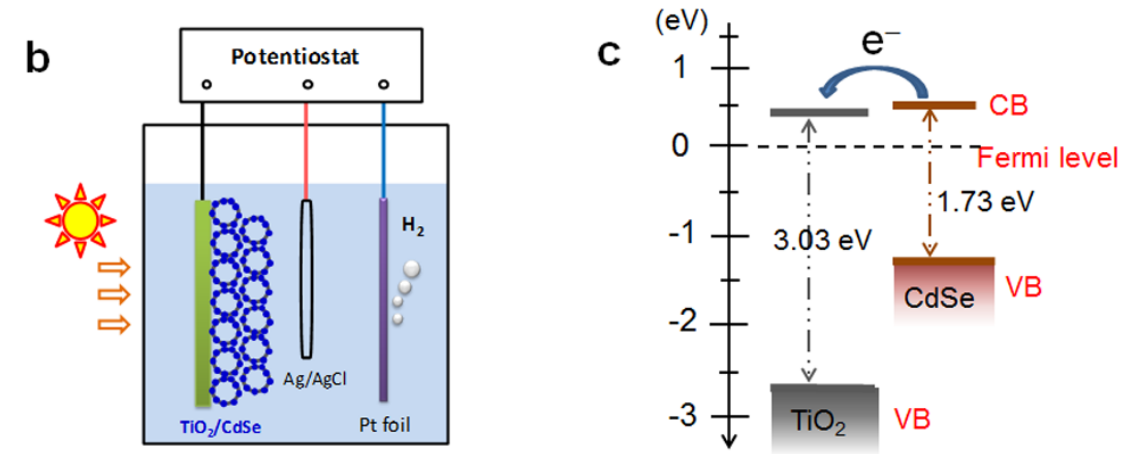

Figure $1 \mid$ Sensitization of $\mathrm{TiO}_{2}$ inverse opals photoelectrochemical anode by ALDIER. (a) Schematics of the ALDIER process for uniform QD photosensitization of $\mathrm{TiO}_{2}$ inverse opals (TiIO). Step 1: coating the TiIO with ALD ZnO layer. Step 2: anion exchange reaction converting the initial ZnO layer to ZnSe. Step 3: cation exchange reactions converting the intermediate ZnSe to CdSe. (b) Schematics of the photoelectrochemical cell: The asprepared nanostructure serves as the anode, saturated $\mathrm{Ag} / \mathrm{AgCl}$ as the reference electrode and the Pt foil as counter electrode for hydrogen evolution. (c) Electron energy levels of $\mathrm{TiO}_{2}$ and $\mathrm{CdSe}$. The photogenerated electrons within CdSe will be transferred to $\mathrm{TiO}_{2}$, while the holes (not drawn) will be scavenged by the $\mathrm{Na}_{2} \mathrm{SO}_{3}+\mathrm{Na}_{2} \mathrm{~S}$ electrolyte solution. $\mathrm{CB}$ : conduction band. VB: valence band. 

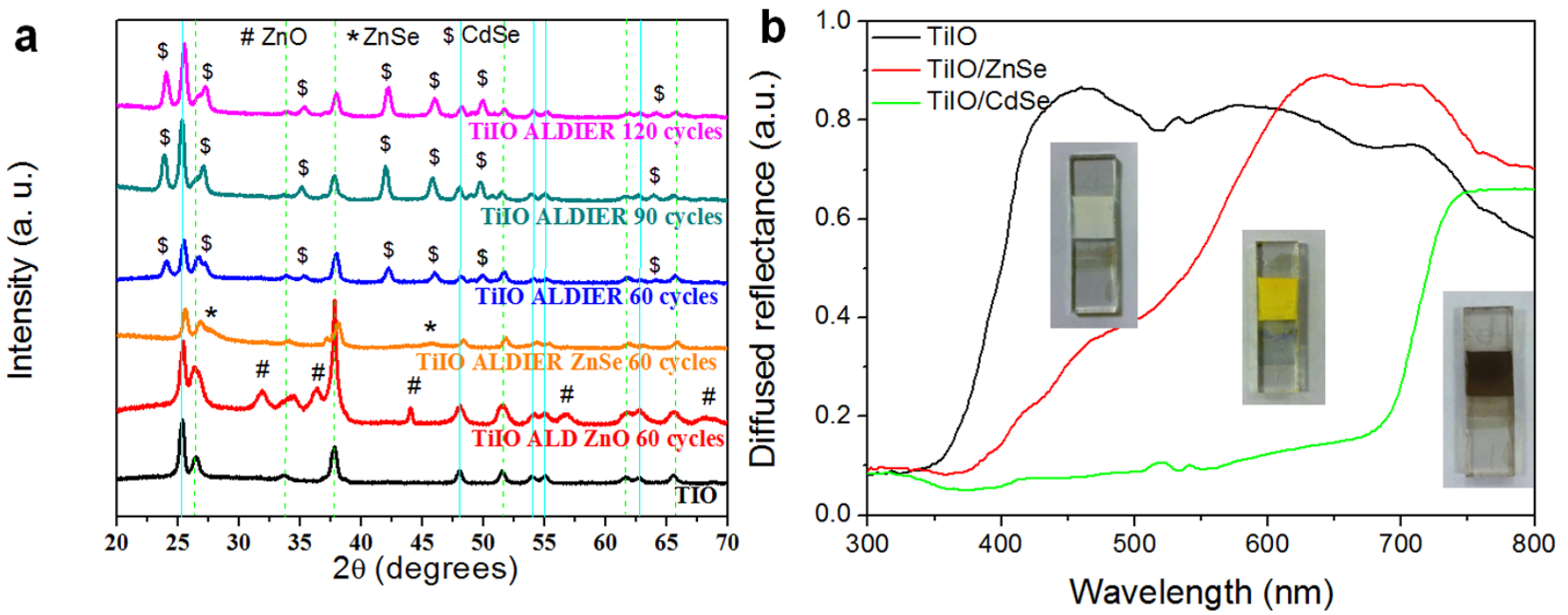

Figure $2 \mid$ Composition transformation. (a) XRD patterns of the pristine TiIO, and the derived structures after ALD and ion exchange reactions. The green dashed lines indicate the peaks of FTO, and the blue solid lines indicate peaks of anatase $\mathrm{TiO}_{2}$. (b) UV-vis diffuse reflection spectra of three photoanode samples. TiIO: pure $\mathrm{TiO}_{2}$ inverse opal. TiIO/ZnSe: $\mathrm{ZnSe}$-coated TiIO after the anion exchange reaction. TiIO/CdSe: CdSe-coated TiIO after the cation exchange reaction. Insets are the photographs of the samples on FTO-coated glass.

increase from the 60-cycle sample to 120 -cycle one, in accordance with the increased loading of CdSe.

UV-visible diffused reflection spectra are recorded to reveal the light harvesting capability of the pristine TiIO, ZnSe and CdSe sensitized TiIO photoanodes (results shown in Fig. 2b). The pristine TiIO can only absorb light with a wavelength below $400 \mathrm{~nm}$. The absorption range broadens up to $550 \mathrm{~nm}$ after the exchange to $\mathrm{ZnSe}$, and $700 \mathrm{~nm}$ after the final exchange into CdSe, consistent with their bandgaps. More diffuse reflection spectra for the samples at intermediate conversion stage are shown in Supplementary Fig. S1. The composition change after anion and cation exchange reactions and the light harvesting ability can also be revealed from the photographs of the samples in Fig. 2b inset. The samples with CdSe coating appear dark brown compared with the bright yellow coloured $\mathrm{ZnSe}$ and white pristine TiIOs.

Morphologies of the photoanodes prior to and after the ion exchange reactions with different ALD $\mathrm{ZnO}$ cycles are shown by SEM images in Fig. 3. The original TiIO surfaces are smooth. After ALDIER, the open surfaces are coated with a granular layer of CdSe. The SEM image in Fig. 3e provides an entire cross-sectional view of the structure with 60 ALD cycles (larger scale SEM images are provided in Supplementary Fig. S2). Clearly the ion exchange reactions proceed along the whole depth of $10 \mu \mathrm{m}$, owing to the effectiveness of ALD in creating conformal coatings on the surfaces of high aspectratio nanostructures. The morphology is further characterized using transmission electron microscopy (TEM). Figure 4a provides clear evidence of the attachment of nanoparticles on the available surfaces of $\mathrm{TiO}_{2}$ pores. High-resolution TEM image in Fig. $4 \mathrm{~b}$ shows that the particles are crystalline, and the lattice spacing can be indexed into (0-11) and (1-1-1) planes of hexagonal CdSe. Pure elements of Cd and $\mathrm{Se}$ are confirmed by the X-ray energy dispersion spectrum shown in Fig. 4c.

The PEC performance of the ALDIER photoanodes is investigated by conducting the current density vs potential $(J-V)$ measurements under the dark and simulated sunlight illumination (AM 1.5) in the three-electrode cell configuration (Fig. 1b). First of all, all the electrodes are fabricated from $500 \mathrm{~nm}$ polystyrene spheres and have the same height of $10 \mu \mathrm{m}$. For ion exchange reaction, temperature is a critical parameter that affects the size and morphology of the resulting sensitizer layer. Hence the first step is to optimize the reaction temperature for CdSe exchange reaction while keeping ALD ZnO thickness the same ( $\sim 10 \mathrm{~nm}$ by 60 ALD cycles). As shown in Supplementary Fig. S3, the electrode obtained from the reaction at $120^{\circ} \mathrm{C}$ exhibits the highest photocurrent level $\left(15.7 \mathrm{~mA} / \mathrm{cm}^{2}\right.$ at zero bias vs $\mathrm{Ag} / \mathrm{AgCl})$ compared to those from reactions at $90^{\circ} \mathrm{C}(4.6 \mathrm{~mA} /$ $\left.\mathrm{cm}^{2}\right)$ and $140^{\circ} \mathrm{C}\left(10.5 \mathrm{~mA} / \mathrm{cm}^{2}\right)$. Therefore, for the rest experiments, the reaction temperature is fixed at $120^{\circ} \mathrm{C}$. Figure 5 a presents the $J-V$
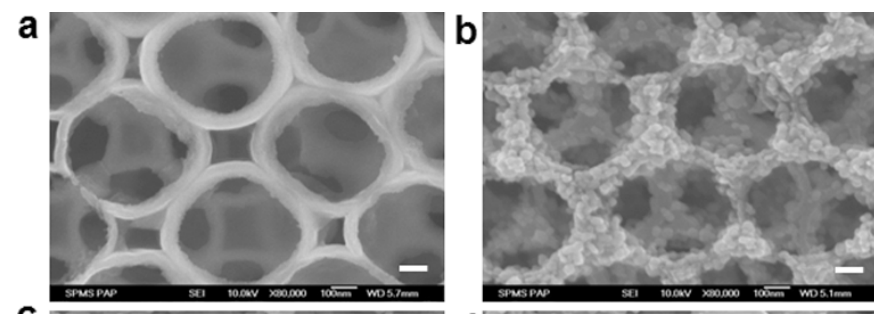

C
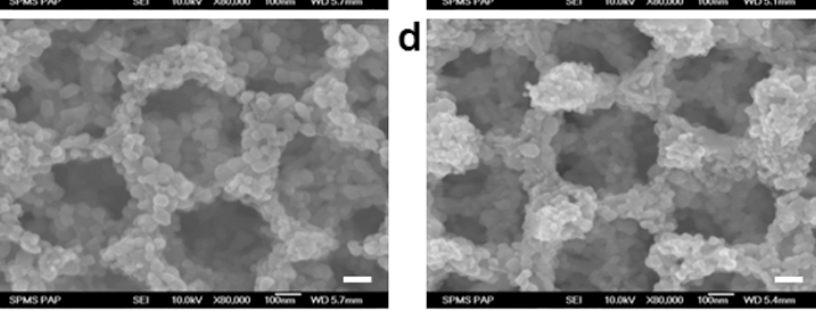

e

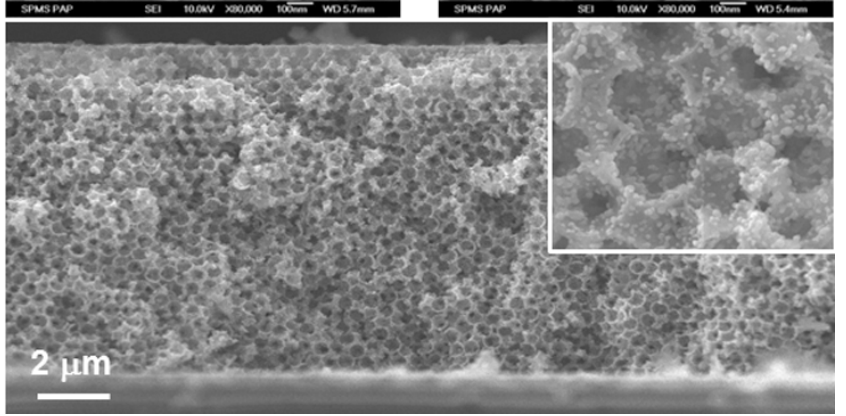

Figure $3 \mid$ SEM characterization. (a) Top view of the pristine $\mathrm{TiO}_{2}$ inverse opal. (b-d) Top view images of the ALDIER samples, where the CdSe layers were converted from the $\mathrm{ZnO}$ starting layers obtained by using 60, 90, and 120 ALD cycles, respectively. Scale bars: $100 \mathrm{~nm}$. (e) Side view of the entire cross section of the photoanode in (b) showing the uniform sensitization from top to the bottom. Inset: enlarged view of part of the cross section. 
a

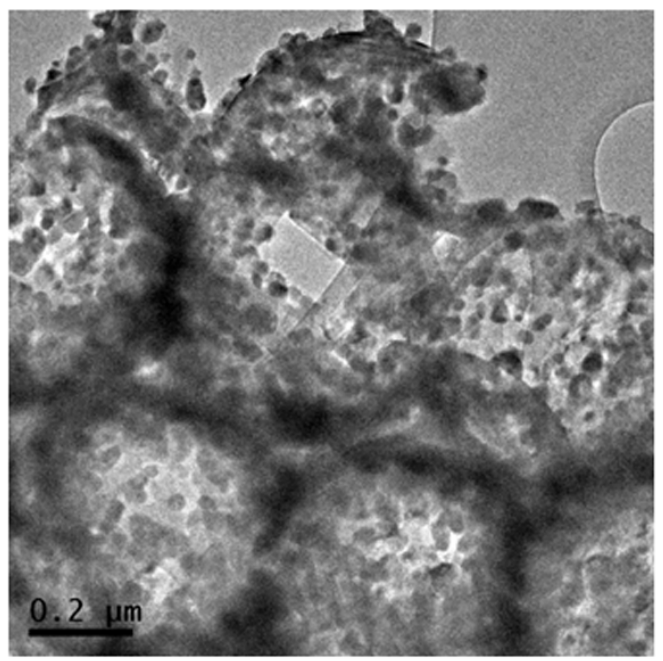

b

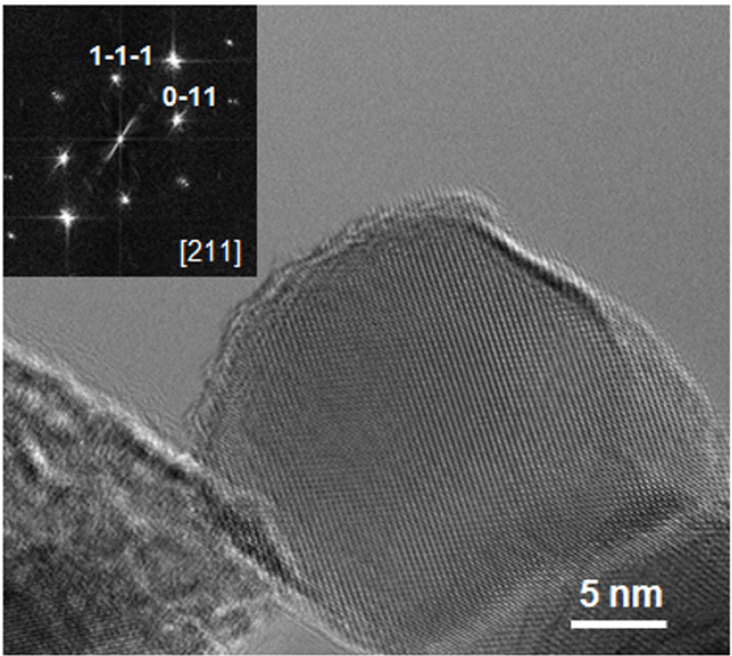

C

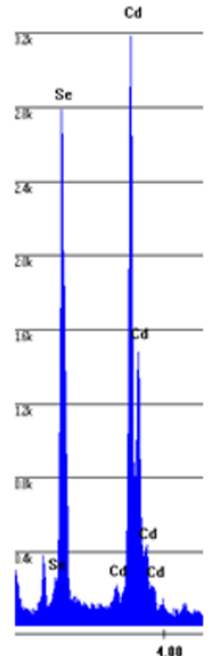

Figure $4 \mid$ TEM characterization. (a) Low-magnification TEM image of the CdSe nanoparticle-sensitized $\mathrm{TiO}_{2}$ inverse opal. (b) Atomic-scale TEM image of one CdSe nanoparticle. Inset is the corresponding fast Fourier transformation pattern. (c) X-ray energy dispersion spectrum (EDS) recorded from the CdSe nanoparticle in (b).

curves of TiIO/CdSe anodes obtained from different ZnO ALD cycles. All the photoanodes present negligible dark currents while showing current densities above $10 \mathrm{~mA} / \mathrm{cm}^{2}$, upon illumination. This implies an efficient light harvesting by the sensitizers (see also IPCE below) and charge separation at the $\mathrm{TiO}_{2}$ and CdSe interface rendered by the type-II band alignment (see Fig. 1c). All the samples show similar onset potentials $(-1.0 \mathrm{~V}$ vs $\mathrm{Ag} / \mathrm{AgCl})$, as a result of similar surface flat bands. The photocurrents saturate a

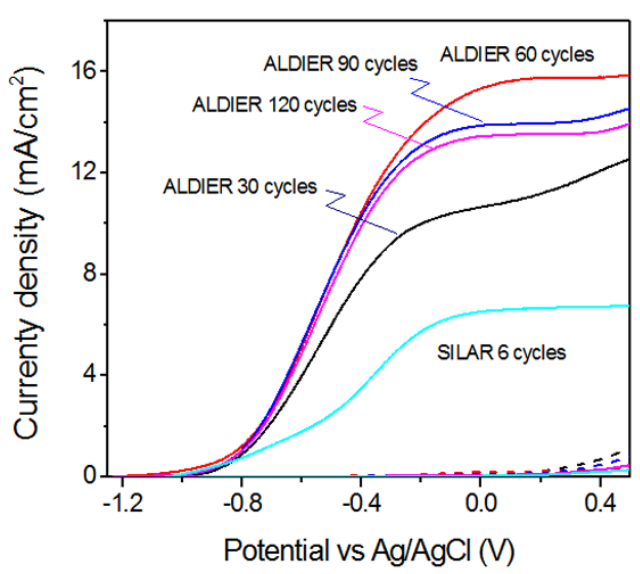

C

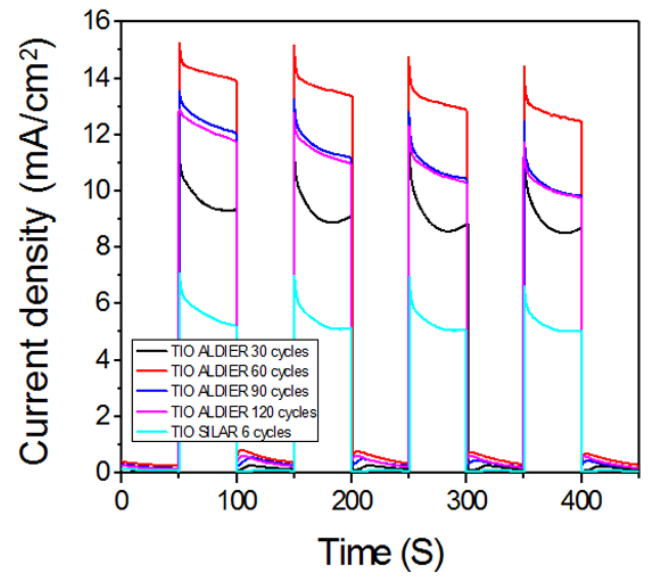

b

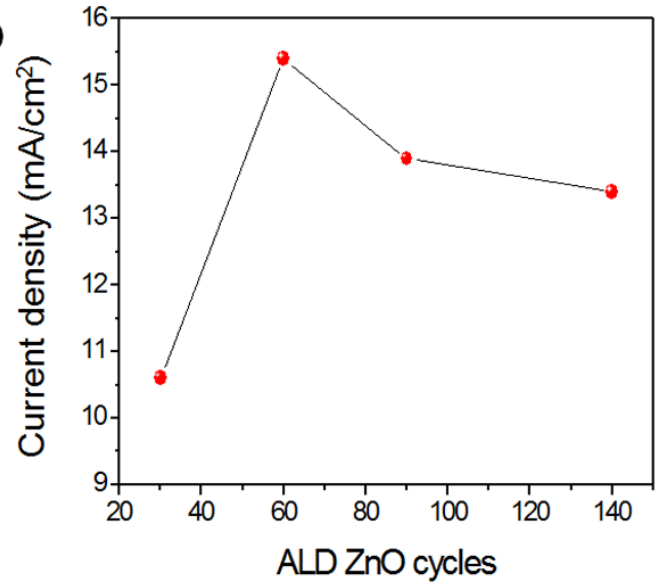

d

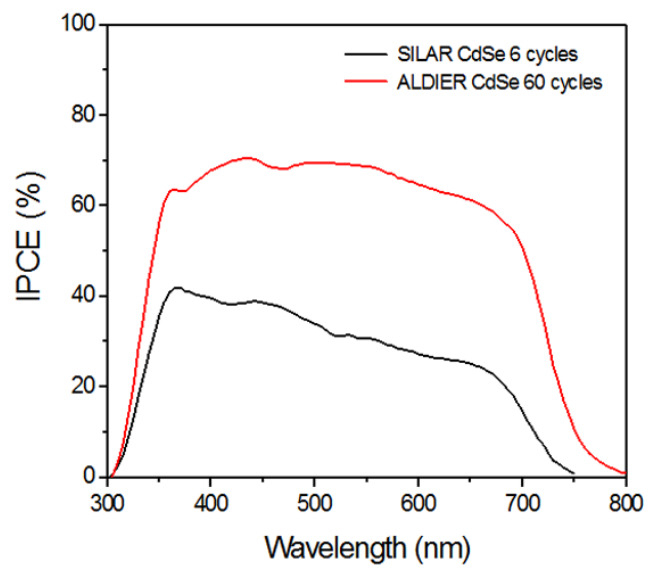

Figure $5 \mid$ Photoelectrochemical properties of the ALDIER $\mathrm{TiO}_{2}$ inverse opal photoanodes. (a) Linear sweep voltammagrams ( $J$ - $V$ curves) under dark condition and AM1.5 light illumination for samples by ALDIER technique with different ALD cycles, and one by 6 SILAR cycles. (b) Plot of the photocurrent density at zero bias in (a) versus the ALD ZnO cycle. (c) Photocurrent versus time tests ( $J-\mathrm{t}$ curves) under chopped light illumination (light/dark cycles of $50 \mathrm{~s}$ ) at a fixed bias of $0 \mathrm{~V}$ vs Ag/AgCl. (d) IPCE profile of the ALDIER photoanode with 60 ALD cycles. For comparison, the corresponding data of the optimized SILAR anode (6 cycles CdSe) are also shown. 
with increasing bias voltage, indicating the good electrical conductivity of the TiIO/CdSe and the good contacts with the FTO.

We now discuss the effect of ALD ZnO thickness. Figure 5a-c show that the sample from 60 ALD cycles gives the highest photocurrents; further increment of the number of ALD cycles to 90 and 120 slightly bring the photocurrent down to $\sim 13 \mathrm{~mA} / \mathrm{cm}^{2}$. The lowering of the current with higher ALD cycles might originate from adverse effects such as increased carrier recombination within the thicker CdSe layers. It is noted that a thicker ALD ZnO layer corresponds to a larger CdSe nanoparticle size. The photocurrent versus time $(J-\mathrm{t})$ curves in Fig. $5 \mathrm{c}$ show that all the electrodes have good photoresponse and relatively good stability. For a comparison, a series of control samples of the same height are sensitized with CdSe via the SILAR method and measured under the same condition (see SEM images in Supplementary Fig. S4). Among samples with 3, 6, and 9 SILAR cycles, the highest photocurrent is $\sim 6.5 \mathrm{~mA} / \mathrm{cm}^{2}$ obtained from the 6-cycle SILAR sample (also presented in Fig. 5a). The CdSe nanoparticles appear to have a lower coverage than that by ALDIER based on SEM inspection, which is consistent with the diffuse reflectance data, that is, the SILAR samples have a higher diffuse reflectance compared to that of ALDIER samples (see Supplementary Fig. S5 and Fig. S1). It is noteworthy that the photocurrent level obtained from our ALDIER electrodes is very high among nano $\mathrm{TiO}_{2}$ photoanodes, even higher than the previously reported $\mathrm{TiO}_{2}$ nanoparticle electrode with $\mathrm{CdS}$ and CdSe cosensitization $\left(14.9 \mathrm{~mA} / \mathrm{cm}^{2}\right)^{31}$.

While the voltammagram $J-V$ curves show the overall PEC performance of the photoanode, the insight of the wavelengthdependent photocarrier generation can be obtained by studying the incident-photon-to-current conversion efficiency (IPCE), which allows the evaluation of the wavelength-dependent light harvesting efficiency. The IPCE profile from the 60-ALD cycle sample is shown in Fig. 5d. One can see that, within the test range of $300-800 \mathrm{~nm}$ wavelength, a strong and nearly constant photoresponse is observed in the visible region from 305 to $750 \mathrm{~nm}$; the efficiency lies between $60-70 \%$ with a nearly flat profile. In contrast, the IPCE of the photoanode by SILAR sensitization is significantly lower, probably due to the aforementioned lower coverage of CdSe and the non-uniform sensitization, in correlation with its higher light reflectivity.

\section{Discussion}

The significant performance enhancement of ALDIER anodes compared with SILAR ones implies the superior quality of the sensitizer coating by this simple yet powerful ALD plus ion exchange technique, which results in an excellent penetration depth, uniform coverage and increased amount of loading of the sensitizers. As a result, both the light harvesting ability and the charge transfer would be enhanced. It is envisaged that the performance could be further improved by $\mathrm{ZnS}$ passivation as reported previously $\mathrm{y}^{32}$ or by doping of CdSe which is recently developed by the Kamat group ${ }^{33}$.

To generalize this ALDIER technique to various nanostructures, same experiments are also conducted to $\mathrm{TiO}_{2}$ nanorod arrays and nanoparticle films (see Supplementary Fig. S6 and S7). Shown in Fig. S6 are the results from the commercial P25 nanoparticle film. Clearly, one can also see the very low diffused reflectance and a high photocurrent level up to $12 \mathrm{~mA} / \mathrm{cm}^{2}$. The detailed study of the interface between $\mathrm{CdSe}$ and $\mathrm{TiO}_{2}$ by the HRTEM and the inner charge transfer process by ultrafast optical spectroscopy is currently underway to provide a comprehensive physical understanding.

The demonstrated fabrication process can also readily result in $\mathrm{CdS}$ and $\mathrm{PbSe}$ if the anion exchange precursor is $\mathrm{S}^{2-}$ and the cation exchange precursor is $\mathrm{Pb}^{2+}$, respectively. Due to the high conformity of the ALD ZnO layer ${ }^{34}$, this simple two-step ALDIER process can be utilized for homogeneous coating of photoactive CdS, CdSe, PbS, or $\mathrm{PbSe}$ nanoparticles onto a wide range of complex and high-aspectratio substrates. Furthermore, as the thickness of the $\mathrm{ZnO}$ layer is precisely tunable by ALD cycles, the self-limiting ion exchange reaction will thus lead to different size and coverage of the final sensitizer nanoparticles.

To summarize, a new strategy based on ion exchange reaction using ALD ZnO layer as sacrificial template has been developed to coat $\mathrm{TiO}_{2}$ nanostructures with a homogeneous layer of CdSe photosensitizer. With the optimized ion exchange reaction temperature and ALD ZnO thickness, the highest photocurrent for the TiIO/ CdSe electrode reaches $15.7 \mathrm{~mA} / \mathrm{cm}^{2}$ at zero bias (versus $\mathrm{Ag} / \mathrm{AgCl}$ ), which is the highest value among $\mathrm{TiO}_{2}$-based photoelectrochemical cells for hydrogen generation. Further in-depth insights of the enhancement mechanism will be studied in more details. This sensitization method can be generalized to other sensitizers like CdS, PbS, and PbSe. It is optimistic that such ALDIER method is ready to be extended to other $\mathrm{TiO}_{2}$ nanostructures including anodized nanotubes, and to other electron transporting materials like $\mathrm{SnO}_{2}$.

\section{Methods}

Fabrication of $\mathrm{TiO}_{2}$ Inverse Opals. Carboxylate-modified, monodispersed polystyrene spheres of $500 \mathrm{~nm}$ diameter (Duke scientific corporation) were assembled onto the Fluorine-doped $\mathrm{SnO}_{2}$ (FTO) coated glass substrates via a vertical deposition process at $90^{\circ} \mathrm{C}^{29,30}$. The self-assembled polystyrene spheres opals were then infiltrated with $\mathrm{TiO}_{2}$ using a stop-flow-reactor ALD system at $70^{\circ} \mathrm{C}$, for which titanium tetrachloride (99.99\%, Sigma Aldrich) and $\mathrm{H}_{2} \mathrm{O}$ were used as the Ti and $\mathrm{O}$ precursors, respectively. Finally, $\mathrm{TiO}_{2}$ inverse opal structures were developed by burning the original polystyrene spheres in air at $450^{\circ} \mathrm{C}$ for $2 \mathrm{~h}$, which also improved the crystallinity of the $\mathrm{TiO}_{2}$. Last, reactive ion etching (RIE, NSC ES371) was used to cleave the top surface and open up the pores.

Preparation of $\mathrm{TiO}_{2}$ particle film. $\mathrm{TiO}_{2}$ nanoparticle films were deposited on the FTO by successive screen-printing using a $\mathrm{TiO}_{2}$ paste consisting of Degussa $\mathrm{P} 25 \mathrm{TiO}_{2}$ powder and an ethyl cellulose binder in $\alpha$-terpinol ${ }^{35}$. The projected area of the $\mathrm{TiO}_{2}$ layers was approximately $0.28 \mathrm{~cm}^{2}$ (circles with $0.6 \mathrm{~cm}$ diameter). Then, the $\mathrm{TiO}_{2}$ electrodes were gradually heated to $450^{\circ} \mathrm{C}$ where they were held for $15 \mathrm{~min}$ before being heated to $500^{\circ} \mathrm{C}$ for a further $30 \mathrm{~min}$.

ALD ZnO layer and Ion Exchange Reactions. ZnO layers with different thickness were conformably deposited onto the TiIO as the sacrificial layers for the ion exchange reaction by ALD with the Diethyl zinc (DEZ, 99.99\%, Sigma Aldrich) and $\mathrm{H}_{2} \mathrm{O}$ as the $\mathrm{Zn}$ and $\mathrm{O}$ precursors, respectively. The $\mathrm{ZnO}$ coated TiIOs were then annealed in air at $450^{\circ} \mathrm{C}$ for 30 minutes to improve the crystallinity. TiIO/ZnSe core/ shell structure was prepared by immersing the $\mathrm{ZnO}$ coated $\mathrm{TiIO}$ in a $\mathrm{Se}^{2-}$ ion solution $(0.05 \mathrm{M}$, prepared by reacting $0.79 \mathrm{~g}$ Se powder with $0.8 \mathrm{~g} \mathrm{NaBH} 4$ in $200 \mathrm{ml}$ deionized water) and kept at $60^{\circ} \mathrm{C}$ for 5 hours in order to fully exchange the $\mathrm{ZnO}$ layer into $\mathrm{ZnSe}^{27}$. The samples were then washed with deionized water and absolute ethanol and fiwater dried in air. Due to the fact that $\mathrm{Se}^{2-}$ is vulnerable to oxygen, all the experiments containing $\mathrm{Se}^{2-}$ ions were done in glove box. The TiIO/ZnSe core/shel structures were then reacted with the $0.1 \mathrm{M} \mathrm{CdCl}_{2} \cdot 2.5 \mathrm{H}_{2} \mathrm{O}$ aqueous solution at $90-140^{\circ} \mathrm{C}$ for 10 hours to replace $\mathrm{Zn}^{2+}$ by $\mathrm{Cd}^{2+}$ in the $\mathrm{ZnSe}$ shell. By controlling the reaction temperature, the composition of the $\mathrm{TiO} / \mathrm{Zn}_{\mathrm{x}} \mathrm{Cd}_{1-\mathrm{x}} \mathrm{Se}$ core/shell structure could be tuned. Finally, $\mathrm{TIO} / \mathrm{Zn}_{\mathrm{x}} \mathrm{Cd}_{1-\mathrm{x}} \mathrm{Se}$ core/shell nanostructure was annealed in argon ambient at $400^{\circ} \mathrm{C}$ for 30 minutes to improve crystallinity.

Successive Ionic Layer Adsorption and Reaction (SILAR) of CdSe on TiIO. The SILAR process was modified from the previous reports ${ }^{15,17}$. In a typical procedure, the TiIO electrodes were immersed in a solution containing $0.05 \mathrm{M}$ cadmium acetate dihydrate $\left(\mathrm{Cd}(\mathrm{Ac})_{2} \cdot 2 \mathrm{H}_{2} \mathrm{O}\right.$, Alfa Aesar, $\left.98 \%\right)$ in ethanol for $1 \mathrm{~min}$, to allow $\mathrm{Cd}^{2+}$ to adsorb onto the $\mathrm{TiO}_{2}$ surface, and then rinsed with ethanol for $1 \mathrm{~min}$ to remove the excess $\mathrm{Cd}^{2+}$. The electrodes were then dried for $2 \mathrm{~min}$ in an argon atmosphere. Subsequently, the dried electrodes were dipped in to a solution containing $0.05 \mathrm{M} \mathrm{Se}^{2}$ for $1 \mathrm{~min}$. The $\mathrm{Se}^{2-}$ solution was prepared by mixing selenium (Se, Sigma-Aldrich, $99.8 \%$ ) and sodium borohydride (NaBH4, Sigma Aldrich, 99.8\%) in water. The electrodes were then rinsed in ethanol for $1 \mathrm{~min}$ and dried again in an argon atmosphere for another $2 \mathrm{~min}$. This procedure was repeated several times to get desired CdSe loading.

Materials Characterizations. The morphology and microstructure of the nanostructured films were examined using a JEOL JSM-7600F field emission scanning electron microscopy (FE-SEM), and a JEM 2100F transmission electron microscope (TEM). The X-ray diffraction (XRD) patterns were recorded by Shimadzu thin film XRD equipment using $\mathrm{Cu} K \alpha$ radiation. The diffuse reflection spectra were taken using Zolix Solar Cell QE/IPCE Measurement System equipped with an integrating sphere and a silicon diode detector.

Photoelectrochemical Characterizations. The PEC performance measurements were conducted in three electrodes configuration with the as prepared nanostructured photoanodes as working electrodes, $\mathrm{Ag} / \mathrm{AgCl}$ in saturated $\mathrm{KCl}$ as a reference electrode and $\mathrm{Pt}$ foil as the counter electrode. $0.24 \mathrm{M} \mathrm{Na}_{2} \mathrm{~S}$ and $0.35 \mathrm{M}$ 
$\mathrm{Na}_{2} \mathrm{SO}_{3}$ mixed aqueous solution was used as the electrolyte. The current density vs potential $(J-V)$ measurements were measured in both dark and illumination with a 150W Xe lamp (Science tech SS150) equipped with an AM1.5 G filter, calibrated with a standard Si solar cell to simulate AM1.5 illumination $\left(100 \mathrm{~mW} / \mathrm{cm}^{2}\right)$. Photocurrent versus time $(J-t)$ tests were carried out by measuring the currents under chopped light illumination (light/dark cycles of $50 \mathrm{~s}$ ) at a fixed bias of $0 \mathrm{~V}$ versus $\mathrm{Ag} / \mathrm{AgCl}$. The incident-photon-to-current conversion efficiency (IPCE) measurements were taken as a function of wavelength from 300 to $800 \mathrm{~nm}$ using a specially designed IPCE system for solar cells (Zolix Solar cell Scan100), with three electrodes configuration under zero bias versus $\mathrm{Ag} / \mathrm{AgCl}$. A $300 \mathrm{~W}$ Xe lamp equipped with gratings was used to generate a monochromatic beam. The incident light intensity was calibrated by a standard silicon photodiode.

1. Fujishima, A. \& Honda, K. Electrochemical Photolysis of Water at a Semiconductor Electrode. Nature 238, 37-38 (1972).

2. Chen, X. \& Mao, S. S. Titanium dioxide nanomaterials: Synthesis, properties, modifications, and applications. Chem. Rev. 107, 2891-2959 (2007).

3. Walter, M. G. et al. Solar Water Splitting Cells. Chem. Rev. 110, 6446-6473 (2010).

4. Oregan, B. \& Gratzel, M. A Low-Cost, High-Efficiency Solar-Cell Based on DyeSensitized Colloidal TiO2 Films. Nature 353, 737-740 (1991).

5. Kamat, P. V. Quantum Dot Solar Cells. Semiconductor Nanocrystals as Light Harvesters. J. Phys. Chem. C 112, 18737-18753 (2008).

6. Serpone, N. \& Emeline, A. V. Semiconductor Photocatalysis - Past, Present, and Future Outlook. J. Phys. Chem. Lett. 3, 673-677 (2012).

7. Serpone, N., Borgarello, E. \& Gratzel, M. Visible-Light Induced Generation of Hydrogen from H2s in Mixed Semiconductor Dispersions - Improved Efficiency through Inter-Particle Electron-Transfer. J. Chem. Soc., Chem. Commun. 342-344 (1984).

8. Alivisatos, A. P. Semiconductor Clusters, Nanocrystals, and Quantum Dots. Science 271, 933-937 (1996).

9. Peng, Z. A. \& Peng, X. Formation of High-Quality CdTe, CdSe, and CdS Nanocrystals Using CdO as Precursor. J. Am. Chem. Soc. 123, 183-184 (2000).

10. Robel, I., Subramanian, V., Kuno, M. \& Kamat, P. V. Quantum Dot Solar Cells. Harvesting Light Energy with CdSe Nanocrystals Molecularly Linked to Mesoscopic TiO2 Films. J. Am. Chem. Soc. 128, 2385-2393 (2006)

11. Mora-Sero, I. \& Bisquert, J. Breakthroughs in the Development of SemiconductorSensitized Solar Cells. J. Phys. Chem. Lett. 1, 3046-3052 (2010).

12. Watson, D. F. Linker-Assisted Assembly and Interfacial Electron-Transfer Reactivity of Quantum Dot-Substrate Architectures. J. Phys. Chem. Lett. 1, 22992309 (2010).

13. Niitsoo, O. et al. Chemical bath deposited CdS/CdSe-sensitized porous $\mathrm{TiO} 2$ solar cells. J. Photochem. Photobiol. A Chem. 181, 306-313 (2006).

14. Chang, C. H. \& Lee, Y. L. Chemical bath deposition of CdS quantum dots onto mesoscopic TiO2 films for application in quantum-dot-sensitized solar cells. Appl. Phys. Lett. 91 (2007)

15. Lee, H. J., Bang, J., Park, J., Kim, S. \& Park, S.-M. Multilayered Semiconductor (CdS/CdSe/ZnS)-Sensitized TiO2 Mesoporous Solar Cells: All Prepared by Successive Ionic Layer Adsorption and Reaction Processes. Chem. Mater. 22, 5636-5643 (2010).

16. Lee, H. et al. Efficient CdSe Quantum Dot-Sensitized Solar Cells Prepared by an Improved Successive Ionic Layer Adsorption and Reaction Process. Nano Lett. 9, 4221-4227 (2009).

17. Hossain, M. A., Jennings, J. R., Koh, Z. Y. \& Wang, Q. Carrier Generation and Collection in CdS/CdSe-Sensitized SnO2 Solar Cells Exhibiting Unprecedented Photocurrent Densities. ACS Nano 5, 3172-3181 (2011).

18. Banerjee, S., Mohapatra, S. K., Das, P. P. \& Misra, M. Synthesis of Coupled Semiconductor by Filling 1D TiO2 Nanotubes with CdS. Chem. Mater. 20, 67846791 (2008).
19. Lee, J.-C., Kim, T. G., Lee, W., Han, S.-H. \& Sung, Y.-M. Growth of CdS NanorodCoated TiO2 Nanowires on Conductive Glass for Photovoltaic Applications. Crystal Growth \& Design 9, 4519-4523 (2009).

20. Islam, M. A., Xia, Y., Telesca, D. A., Steigerwald, M. L. \& Herman, I. P. Controlled Electrophoretic Deposition of Smooth and Robust Films of CdSe Nanocrystals. Chem. Mater. 16, 49-54 (2003).

21. George, S. M. Atomic Layer Deposition: An Overview. Chem. Rev. 110, 111-131 (2010).

22. Brennan, T. P. et al. Atomic Layer Deposition of CdS Quantum Dots for SolidState Quantum Dot Sensitized Solar Cells. Adv. Energy Mater. 1, 1169-1175 (2011).

23. Son, D. H., Hughes, S. M., Yin, Y. \& Paul Alivisatos, A. Cation Exchange Reactions in Ionic Nanocrystals. Science 306, 1009-1012 (2004).

24. Robinson, R. D. et al. Spontaneous Superlattice Formation in Nanorods Through Partial Cation Exchange. Science 317, 355-358 (2007).

25. Tang, J., Huo, Z., Brittman, S., Gao, H. \& Yang, P. Solution-processed core-shell nanowires for efficient photovoltaic cells. Nat. Nanotechnol. 6, 568-572 (2011).

26. Myung, Y. et al. Composition-Tuned $\mathrm{ZnO}-\mathrm{CdSSe}$ Core-Shell Nanowire Arrays. ACS Nano 4, 3789-3800 (2010).

27. Xu, J. et al. Arrays of $\mathrm{ZnO} / \mathrm{ZnxCd} 1-\mathrm{xSe}$ Nanocables: Band Gap Engineering and Photovoltaic Applications. Nano Lett. 11, 4138-4143 (2011).

28. Fan, H. J., Yang, Y. \& Zacharias, M. ZnO-based ternary compound nanotubes and nanowires. J. Mater. Chem. 19, 885-900 (2009).

29. Liu, L., Karuturi, S. K., Su, L. T. \& Tok, A. I. Y. TiO2 inverse-opal electrode fabricated by atomic layer deposition for dye-sensitized solar cell applications. Energy Environ. Sci. 4, 209-215 (2011).

30. Cheng, C. W. et al. Quantum-Dot-Sensitized TiO2 Inverse Opals for Photoelectrochemical Hydrogen Generation. Small 8, 37-42 (2012).

31. Lee, Y.-L., Chi, C.-F. \& Liau, S.-Y. CdS/CdSe Co-Sensitized TiO2 Photoelectrode for Efficient Hydrogen Generation in a Photoelectrochemical Cell. Chem. Mater. 22, 922-927 (2009).

32. Mora-Seró, I. n. et al. Recombination in Quantum Dot Sensitized Solar Cells. Acc. Chem. Res. 42, 1848-1857 (2009).

33. Santra, P. K. \& Kamat, P. V. Mn-Doped Quantum Dot Sensitized Solar Cells: A Strategy to Boost Efficiency over 5\%. J. Am. Chem. Soc. 134, 2508-2511 (2012).

34. Yamada, A., Sang, B. \& Konagai, M. Atomic layer deposition of $\mathrm{ZnO}$ transparent conducting oxides. Appl. Surf. Sci. 112, 216-222 (1997).

35. Jennings, J. R., Liu, Y., Safari-Alamuti, F. \& Wang, Q. Dependence of DyeSensitized Solar Cell Impedance on Photoelectrode Thickness. J. Phys. Chem. C 116, 1556-1562 (2011).

\section{Author contributions}

JSL, SKK, and HJF designed the experiment, LJL fabricated the polystyrene inverse opals, LTS provided figure 4. JSL and SKK conducted the ALD and all characterizations. HJF and JSL wrote the manuscript text. AIYT provided part of the financial support. All authors reviewed the manuscript.

\section{Additional information}

Supplementary information accompanies this paper at http://www.nature.com/ scientificreports

Competing financial interests: The authors declare no competing financial interests.

License: This work is licensed under a Creative Commons

Attribution-NonCommercial-NoDerivative Works 3.0 Unported License. To view a copy of this license, visit http://creativecommons.org/licenses/by-nc-nd/3.0/

How to cite this article: Luo, J. et al. Homogeneous Photosensitization of Complex $\mathrm{TiO}_{2}$ Nanostructures for Efficient Solar Energy Conversion. Sci. Rep. 2, 451; DOI:10.1038/ srep00451 (2012). 